\title{
Uso adequado de casa-de-vegetação e de telados na experimentação agrícola
}

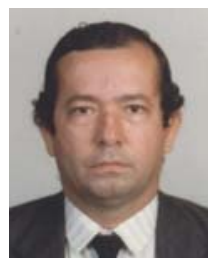

Napoleão E. de M. Beltrão1, José Fideles Filho² \& Ivana C. de M. Figueirêdo ${ }^{3}$

\author{
1 Embrapa Algodão. E-mail: nbeltrao@cnpa.embrapa.br (Foto) \\ 2 UEPB/EMEPA-PB. Estrada da Imbaúba, km 3, Lagoa Seca, PB. Fone: (83) 366-1298. E-mail: fideles@uepb.rpp.br \\ ${ }^{3}$ DEAg/CCT/UFCG. Fone: (83) 342-2744. E-mail: ivanacmf@yahoo.com.br.
}

Protocolo $32-26 / 3 / 2002$

\begin{abstract}
Resumo: Neste trabalho, objetivou-se aglutinar elementos para o uso mais adequado de casasde-vegetação e telados, com a finalidade de experimentação agrícola. São discutidos os fatores água, temperatura do ar e irradiância solar no interior de coberturas artificiais, bem como o manejo do ambiente em termos de tamanho de vasos, seu posicionamento nas casas-de-vegetação e o uso da água de irrigação. Deve-se evitar telas de cor verde (reflete o verde e absorve o vermelho, usado na fotossíntese) e se deve ter os vasos sempre da mesma cor e tamanho.
\end{abstract}

Palavras-chave: Irradiação solar, temperatura do ar, umidade relativa do ar, espectro da irradiação solar, cores de tela e vasos

\section{Appropriate use of greenhouse in the agricultural experimentation}

\begin{abstract}
This paper reviews the main factors affecting the use of greenhouses in agricultural experimentation. The effects of water quality, air temperature and solar irradiance are discussed along with size, placement and color of pots/recipients and use of water in irrigation. Green screen should be avoided in greenhouses as they reflect the green light while absorbing the photosynthetically active red light. All the pots/recipients must be of the same color and size.
\end{abstract}

Key words: solar irradiation, air temperature, relative humidity, solar light spectrum, screen and pot color

\section{INTRODUÇÃO}

No mundo, uma parte significativa da pesquisa agrícola e da produção de algumas plantas ornamentais e hortaliças é feita em casas-de-vegetação ou telados (casas de plástico não climatizadas), na maioria dos casos, sem controle do ambiente (luz, irradiação solar global, irradiação infravermelha e calórica, umidade relativa e temperatura do ar). A nível global, em 1995, existia uma área de 300.000 ha de casas-de-vegetação (vidro e plástico) sendo que, no Brasil, havia 1000 ha de estufas, utilizadas para o cultivo de plantas ornamentais, hortaliças e mudas de várias espécies de plantas; na área científica, cerca de 40 ha de casas-de-vegetação (Oliveira, 1995), representando, segundo o mesmo autor, $35,29 \%$ de casas de vidro, $37,81 \%$ de plástico (polietileno) e 21,84\% do tipo guarda-chuva. Ao longo de mais de 25 anos de pesquisas no campo e em casas-devegetação (vidro, plástico, telados, abertos e fechados e casas de guarda-chuva) em várias localidades do Brasil, em especial no Nordeste, próximo ao Equador, verificou-se que existem resultados para uma mesma variável e fator estudados, dentro de uma mesma espécie e até cultivar, obtidos em casa-de- vegetação, contraditórios e muitas vezes opostos, devido a uma série de fatores aqui chamados de passíveis de controle e os incontroláveis intrínsecos e extrínsecos. Entre tais fatores destacam-se: orientação e estrutura da casa de vegetação, tamanho, tipo e cor dos vasos, cultura a ser estudada e objetivos do trabalho (tipo de estudo, variáveis e fatores a serem estudados). Neste trabalho, de caráter informativo, procurouse relacionar as principais causas de erros ou problemas que ocorrem com frequência em estudos de casas-de-vegetação e telados, e algumas sugestões e recomendações técnicas para solucionar os problemas.

\section{CONSIDERAÇÕES GERAIS}

A casa-de-vegetação é uma estrutura coberta e abrigada artificialmente com materiais transparentes para proteger as plantas contra os agentes meteorológicos exteriores, sendo que no seu interior se pode cultivar os mais diversos tipos de plantas. Oliveira (1995) afirmou que há quatro tipos de estrutura de casade-vegetação: de vidro climatizadas; de vidro semi-climatizadas, produzindo o efeito estufa; casas de plástico semi-climatizadas, 
efeito estufa presente e casas de plástico tipo "guarda-chuva", as quais não são climatizadas. Além das casas-de-vegetação, existem os chamados telados, que podem ser totalmente cobertos ou semi-cobertos, com as laterais livres, cobertos de plástico transparente, ou telas de cor branca, e as vezes verde, que deixam o vento passar parcialmente, e assim deve amenizar a temperatura interna. Para fins de pesquisa, a casa-de-vegetação deve ter, pelo menos, um ou dois pontos de água (torneira), sistema de drenagem (ralos) e uma tomada de energia e iluminação artificial, para trabalhos noturnos. Toda casa-de-vegetação ou telado para a pesquisa, deve ter "bancadas" fixas (cimento e tijolos) ou móveis (hastes de ferro com estrado de madeira), com largura de cerca de $60,0 \mathrm{~cm}$ e comprimento variável de acordo com o tamanho (comprimento) da casa-de-vegetação. De uma bancada para outra deve-se deixar uma distância de pelo menos $80,0 \mathrm{~cm}$ para a circulação. $\mathrm{O}$ piso poderá ser de cimento, em geral sem pintura ou de chão batido no caso de telados. É importante que a casa-de-vegetação tenha duas portas, uma em cada extremo (lados menores), e cobertura de duas águas como pode ser visto na Figura 1.

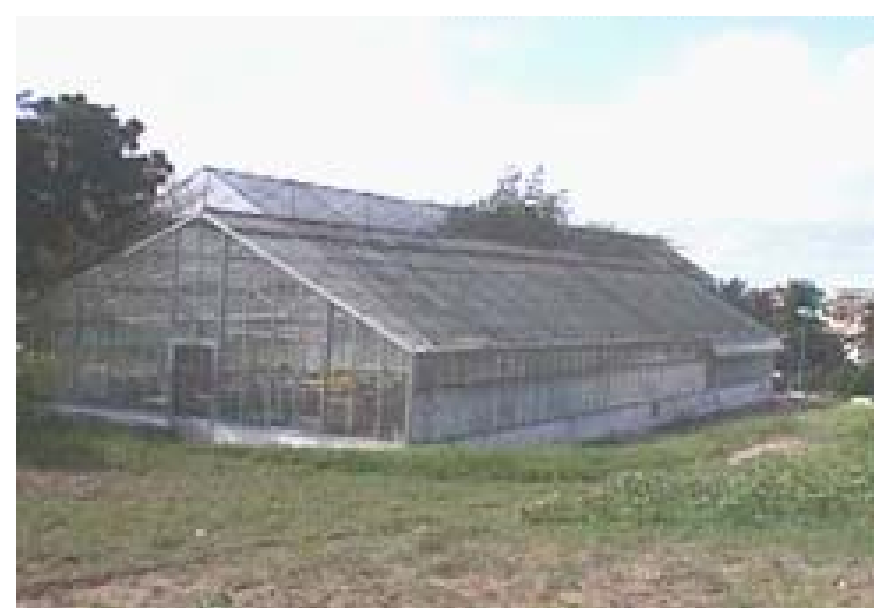

Figura 1. Vista geral de uma casa-de-vegetação de vidro (Embrapa Algodão)

No caso de telados, deve-se dar preferência aos de plástico transparente (passagem da luz) e evitar as telas de cor, em especial a verde, pois reduz demais a luminosidade e a densidade do fluxo radiante no interior do ambiente, causando estiolamento, especialmente em espécies de metabolismo fotossintético $\mathrm{C}_{4}$ (eficientes) ou mesmo $\mathrm{C}_{3}$, que não se saturam com o máximo da irradiância solar, em condições ecofisiológicas, como o algodoeiro herbáceo (Gossypium hirsutum L. raças latifolium Hutch.). No caso do algodoeiro ou plantas $\mathrm{C}_{4}$ (Magalhães, 1979 e Beltrão, 1997) como milho (Zea mays L.), sorgo [Sorghum bicolor (L.) Went] e outras, não deve ser usado telados verde, em um raio de $50 \mathrm{~m}$, não deve haver árvores com altura superior a $5,0 \mathrm{~m}$ e nem construção próxima à casa-de-vegetação, para evitar interferências na luminosidade, radiação solar, ventos etc. (Fig. 2).

\section{PRINCIPAIS PROBLEMAS E SOLUÇÕES}

Em condições ecofisiológicas, a nível de campo, quanto a ambientes restritos, como o caso de casas-de-vegetação e

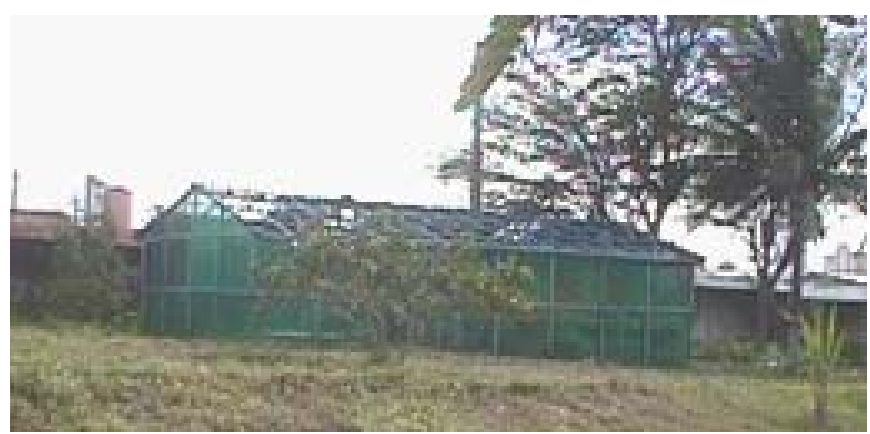

Figura 2. Telado verde, impróprio para o uso com plantas de "sol" e/ou de metabolismo fotossintético $\mathrm{C}_{4}$ (Embrapa Algodão)

telados, os princípios mesológicos funcionam plenamente (Mota, 1976), em especial os dois primeiros, ou seja, os fatores limitantes, ampliação da lei do mínimo e o holocenotismo ambiental, que conduz a interações entre os fatores do ambiente e as reações complexas que ocorrem nas plantas, algumas desconhecidas, outras conhecidas, porém incontroláveis (Beltrão, 1997). Vários fatores que podem ser evitados possibilitando a redução de erros devem ser levados em consideração, tanto na construção da casa-de-vegetação e/ou telado, quanto no planejamento para a condução experimental.

\section{Água}

Quanto à água a ser usada nas plantas em vasos, o ideal é o uso dela destilada ou desmineralizada ou, ainda, a água de chuvas, coletada em cisternas. A água canalizada e tratada deve ser evitada devido aos produtos que contém e também por ser cara. A mais barata é a de cisterna que pode ser captada pela própria casa-de-vegetação; por exemplo, em uma casa-devegetação ou telado pequeno de área de 5,0 x 10,0 m $\left(50 \mathrm{~m}^{2}\right)$ em local que tenha precipitação pluvial anual de $900 \mathrm{~mm}$ $\left(9000 \mathrm{~m}^{3} \mathrm{ha}^{-1}\right)$ ou $\left(900 \mathrm{~L} \mathrm{~m}^{-2}\right)$, tem-se uma quantidade de água captada de $45.000 \mathrm{~L}\left(45 \mathrm{~m}^{3}\right)$, mais que suficiente para o uso na própria casa-de-vegetação. Para reduzir os custos, a cisterna poderá ser feita no solo, que reduz tremendamente o custo e a água poderá ser bombeada até manualmente.

\section{Temperatura}

Nos trópicos, em especial nos meses mais quentes e secos, com temperatura média do ar acima de $25^{\circ} \mathrm{C}$ e umidade relativa do ar, menor que $50 \%$, o que leva a uma grande demanda evaporativa do ar com potencial hídrico do mesmo extremamente baixo, menor que -1000 bars, e com elevada densidade do fluxo radiante ocorre, nas casas-de-vegetação e/ou telados, o denominado "efeito estufa", pois a irradiação solar de elevada energia e baixo comprimento de onda, em especial a luz ( $43 \%$ da radiação solar), com comprimento de onda entre 390 a 700 $\mathrm{nm}$ (Nobel, 1974), passa pelo plástico ou vidro, transforma-se em energia calórica de nível energético menor e maior comprimento de onda, que não consegue passar pela cobertura da estrutura da casa-de-vegetação elevando a sua temperatura interna conforme a lei de Stefan - Boltzmann (a energia emitida por um corpo é proporcional a quarta potência de sua temperatura absoluta $-\mathrm{E}=\varepsilon_{0} \sigma \mathrm{T}^{4}$ ), e lei de Wien, que diz "o comprimento de onda para o qual a emitência espectral de um 
corpo negro é máxima, é inversamente proporcional a sua temperatura absoluta". Desta forma, próximo ao Equador, é comum a temperatura do ambiente dentro da casa-de-vegetação das 12 às $14 \mathrm{~h}$ chegar a ser superior a $50{ }^{\circ} \mathrm{C}$, o que pode prejudicar as plantas, dependendo da espécie, via estresse térmico (Levitt, 1972), com diversos danos. De acordo com Levitt (1972) o calor, como estresse primário, causa diversos tipos de "strains" tais como liquefação de lipídeos, aceleração do metabolismo com incremento do processo respiratório e desnaturação protéica, consideradas elásticas e agregação de proteínas e perda da permeabilidade seletiva das membranas, como “strain" plástico, ou irreversível. Já Larcher (2000) salienta como distúrbios funcionais causados pelo excesso de calor as alterações nas membranas das tilacóides dos cloroplastos e a inibição do fotossistema II, com a depressão da fotossíntese. As plantas tentam resistir ou tolerar o calor, elevando a taxa transpiratória (Levitt, 1972) e/ou aumentando o isolamento térmico, com incremento de ruberina, mecanismos de prevenção via aclimatação ao calor (Larcher, 2000). Com o incremento da radiação infravermelha e da calórica no interior da casa-devegetação, com o consequente aumento da temperatura, pode ocorrer, dependendo da espécie vegetal, da duração do estresse e do estádio do desenvolvimento vegetal, vários danos no metabolismo vegetal, como o incremento anormal da respiração oxidativa e das fotorrespiração nas plantas de metabolismo $\mathrm{C}_{3}$ e a desnaturação de proteínas sensíveis (Levitt, 1972), sendo que em alguns casos pode ocorrer a aclimatação ao calor (Larcher, 2000). Para reduzir tais danos, pode-se atentar para uma das duas alternativas a seguir: estabelecer um sistema de aspersores em cima do teto da casa-de-vegetação, com uma bomba d'água pequena ( 0,5 a 1,0 HP) rotativo, para economizar água, com coletores, ou colocar água no piso da casa, pois cada mol de água (18 g) consome, para vaporizar, 10,5 kcal de energia (Nobel, 1974), o equivalente a $558 \mathrm{cal} \mathrm{g}^{-1}$ de água a temperatura de $25{ }^{\circ} \mathrm{C}$, que é o calor latente de vaporização da água. Neste processo e para se reduzir a umidade relativa do ar, de duas em duas horas, deve-se abrir, as portas da casa-devegetação por períodos de 5 a $10 \mathrm{~min}$.

\section{Luz}

A luz, fração visível da energia solar, que contém a irradiância fotossinteticamente ativa (IFA) compreendida na faixa de 390 a 700 nm (Magalhães 1979; Lacher, 2000), tem importância fundamental em vários processos que ocorrem na planta, especialmente a fotossíntese. O telhado e as laterais da casade-vegetação e/ou telados devem estar sempre limpos, sem poeira impregnada, pois esta reduz substancialmente a luminosidade no interior da casa, causando problemas sérios no crescimento e no desenvolvimento vegetal, reduzindo a fotossíntese e promovendo estiolamento das plantas, que é um pseudo-crescimento. A tela de coloração verde (Fig. 3), bastante utilizada na confecção de telados, reduz consideravelmente a luminosidade no interior da estrutura. Utilizando o espectro-radiômetro de elevada precisão em um dia de pouca nebulosidade ou claro, às $10 \mathrm{~h}$, horário local, realizaram-se medidas fora e dentro de um telado com tela de cor verde e em casa-de-vegetação de vidro, observando-se as diferenças evidenciadas na Figura 4. Verifica-se que, em termos de luz, as diferenças são elevadas, especialmente na faixa compreendida entre 530 a $660 \mathrm{~nm}$, onde tem-se a irradiância solar na faixa do vermelho, utilizada na fotossíntese ao lado da azul e o verde, que é refletida pelas plantas e tela verde, sendo fisicamente complemento do vermelho. A irradiância verde (510 a 610 nm) é fortemente refletida e transmitida pela vegetação e também pela tela verde, até 20 e 40\%, respectivamente (Larcher, 2000), causando uma concentração maior no vermelho distante 700 a 920 nm, não absorvido pela clorofila e a radiação vermelha (610 a $700 \mathrm{~nm}$ ) que é uma das mais absorvidas pela clorofila e, também, pela tela verde, o que reduz a eficiência quântica do aparelho assimilatório das plantas no interior da casa-devegetação coberta com tela verde.

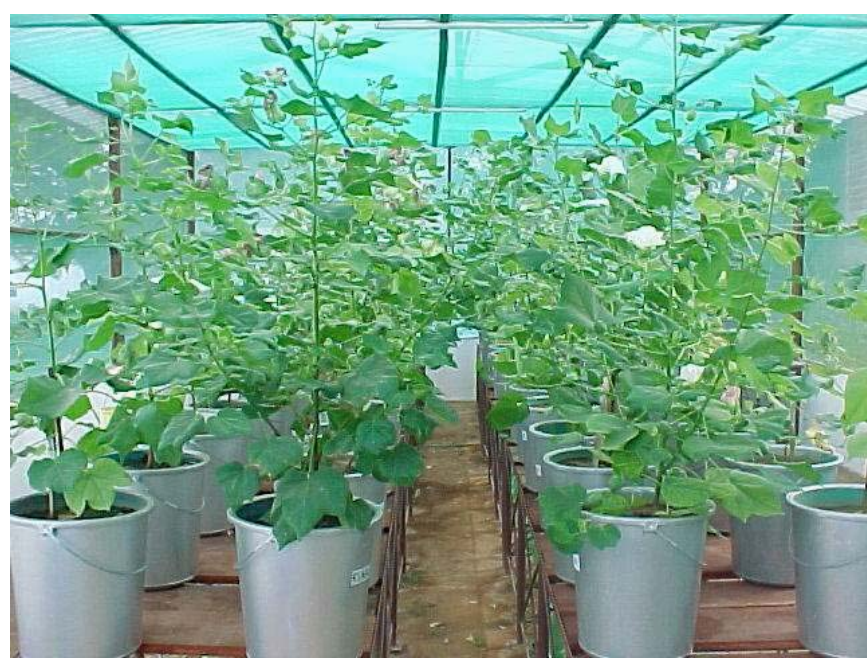

Figura 3. Vista (fundo) de um telado coberto de tela de cor verde (UFCG/PROSAB)

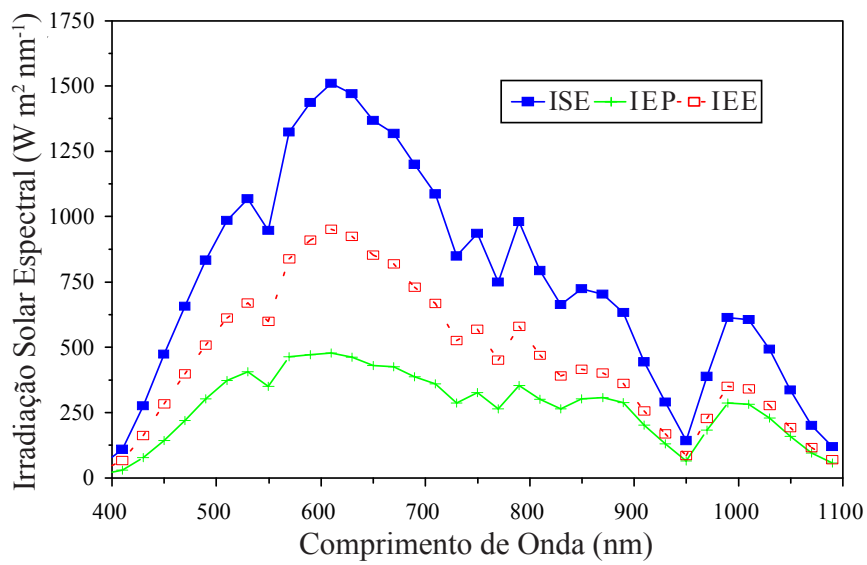

Figura 4. Distribuição da irradiância solar espectral ambiente externo (ISE), dentro da casa-de-vegetação coberta com tela verde - UFCG/PROSAB (IEP) e dentro da casa-de-vegetação coberta com vidro - Embrapa Algodão (IEE), às 10 h local, no mês de março em Campina Grande - PB

Verificou-se, ainda pela Figura 4, que a energia que chega ao interior da casa coberta com vidro é bem maior na iluminância e na IFA, que no telado é inferior à irradiância solar espectral medida fora e ao lado das estruturas consideradas, o que demonstra que se deve usar vidro ou plástico transparente e que os mesmos devem ser limpos periodicamente. 
Tabela 1. Integração da irradiância solar espectral (ISE) na casa-de-vegetação coberto com vidro e com cobertura verde

\begin{tabular}{|c|c|c|c|c|c|c|}
\hline \multirow{3}{*}{ ISE } & \multicolumn{2}{|c|}{ Força } & \multicolumn{4}{|c|}{ Casa de Vegetação } \\
\hline & \multirow{2}{*}{$\begin{array}{l}\text { Valor } \\
\text { Medido }\end{array}$} & \multirow{2}{*}{$\%$} & \multicolumn{2}{|c|}{ Cobertura com Vidro } & \multicolumn{2}{|c|}{ Cobertura Verde } \\
\hline & & & Valor Medido & Redução \% & Valor Medido & Redução \% \\
\hline Integração $(400-700 \mathrm{~nm})\left(\mathrm{W} \mathrm{m}^{-2} \mathrm{~nm}^{-1}\right)$ & $1594 \times 10^{3}$ & 100,00 & $9931 \times 10^{2}$ & 37,69 & $5349 \times 10^{2}$ & 66,44 \\
\hline $\operatorname{IFA}(400-700 \mathrm{~nm})\left(\mu \mathrm{mol} \mathrm{s}^{-1} \mathrm{~m}^{-2}\right)$ & $7765 \times 10^{3}$ & 100,00 & $4841 \times 10^{3}$ & 37,65 & $2595 \times 10^{3}$ & 66,59 \\
\hline Iluminância $(370-790$ nm) (Lux) & $4600 \times 10^{5}$ & 100,00 & $2896 \times 10^{5}$ & 37,04 & $1609 \times 10^{5}$ & 65,13 \\
\hline
\end{tabular}

As magnitudes das diferenças verificadas em cada caso podem ser vistas na Tabela 1 para cada componente, agrupado da irradiância solar. No tocante a distribuição da energia solar dentro da casa de vegetação ou telado, no hemisfério Sul e próximo ao Equador, zona tropical, a estrutura deve ser colocada no sentido Norte-Sul verdadeiro, não tendo os problemas verificados em maiores latitudes (Boulard et al., $2000 \mathrm{e} \mathrm{Li} \mathrm{et} \mathrm{al.,}$ 2000). Verifica-se, nesta tabela, que na casa-de-vegetação, de vidro a redução da irradiância fotossinteticamente ativa (IFA) foi de $37,65 \%$, enquanto que na casa-de-vegetação com tela verde foi de $66,59 \%$, o que afeta muito o desempenho fotossintético das plantas, especialmente de metabolismo $\mathrm{C}_{4}$ que não se satura com o máximo da irradiância solar e apresenta taxa fotossintética de duas a quatro vezes maior do que as plantas de metabolismo fotossintético $C_{3}$ (Street \& Opik, 1974 e Magalhães, 1979) além das modificações nas regiões do vermelho, do verde e do vermelho distante, que é a radiação ativa no fitocromo, proteína que controla diversos processos biológicos nas plantas, inclusive a floração (Kendrick \& Frankland, 1981). Com a redução da irradiância fotossinteticamente ativa no interior das casasde-vegetação e/ou telados, ocorre alterações significativas e de redução nas características funcionais como a atividade dos fotossistemas (I e II), velocidade do transporte eletrônico, atividade da ATP-sintetase, atividade da carboxilase da ribulosefosfato (rubisco), eficiência de carboxilação e capacidade fotossintética (Larcher, 2000), levando às plantas a reduções no crescimento. Nas espécies tolerantes ao "deficit" luminoso, ocorre a um ajustamento, com redução da respiração oxidativa mitocondrial e assim ficando com o saldo de carbono próximo da normalidade para tais espécies, que são, assim, tolerantes ao estresse infraluminoso.

As bancadas que deverão receber os vasos ou bandejas, dependendo do estudo, devem ficar no mesmo sentido (distribuição uniforme da luz e irradiância solar), o que permite o uso de delineamento em blocos ao acaso, sem a necessidade de rodízio (mudança de posição) de vasos que devem ser usados no caso de delineamento inteiramente ao acaso. Na Figura 5, observa-se uma bancada com os vasos já colocados, todos da mesma cor, no sentido Norte-Sul, acompanhando o comprimento maior da casa-de-vegetação. Neste caso, como o Sol caminha no sentido Leste-Oeste (nascente-poente), a distribuição da irradiância solar e a luz no interior da estrutura são bem uniformes dentro de cada bloco, aspecto que não se verifica se a bancada, com o bloco, for colocada no sentido Leste-Oeste, menor comprimento da casa-de-vegetação no caso de ser de forma retangular, fato mais comum.

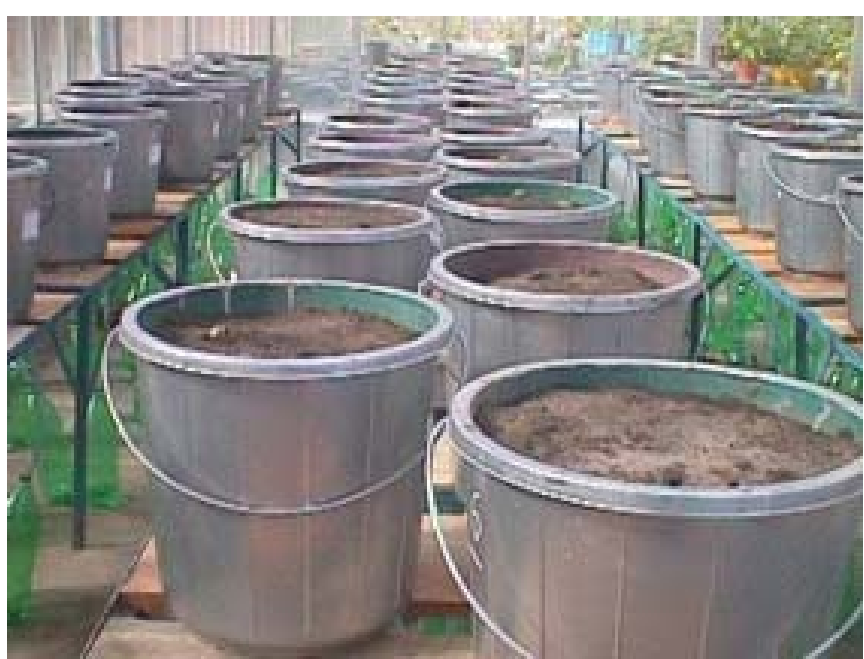

Figura 5. Sentido correto das bancadas com os vasos (sentido Norte-Sul), no interior de uma casa-de-vegetação

\section{ASPECTOS INTERNOS}

\section{Vasos e manejo de água}

Para maior precisão experimental e segurança nos resultados obtidos, o investigador ao trabalhar em casa-de-vegetação ou telado deve tomar outros cuidados, especialmente no tocante aos vasos a serem usados e com o manejo da água de irrigação, além dos que já foram colocados anteriormente. No que diz respeito aos vasos, não deve-se usar recipientes de tamanhos e cores diferentes, em um mesmo estudo. Para culturas de menor porte, como o gergelim (Sesamum indicum L.) e o amendoim (Arachis hipogea L.), os vasos podem ser menores (15 a $20 \mathrm{~L}$ ) pois o crescimento tem alometria definida, que depende da espécie, e cada órgão tem o seu padrão de crescimento e de diferenciação, sendo que a heterogonia entre os diversos órgãos da planta exerce importante papel na morfogênese de todos os orgonismos (Street \& Opik, 1974). A irradiação solar exerce papel fundamental na vida vegetal, com efeitos de fotoenergia (fotossíntese) e de fotoestímulos, como formação de produtos, caso da própria clorofila e de movimentos (Best, 1962) citado por Mota (1976). Na Figura 6 pode-se observar um ensaio de casa-de-vegetação com dois grandes erros: vasos de tamanhos e cores diferentes, o que pode alterar os resultados obtidos, aumentando o erro experimental, o coeficiente de variação e a sensibilidade dos testes estatísticos e assim os resultados obtidos.

Dependendo do tamanho do vaso, a cor altera a sua temperatura e, assim, das plantas que são organismos poiquilotérmicos, sem homeostase (Larcher, 2000), o que pode 


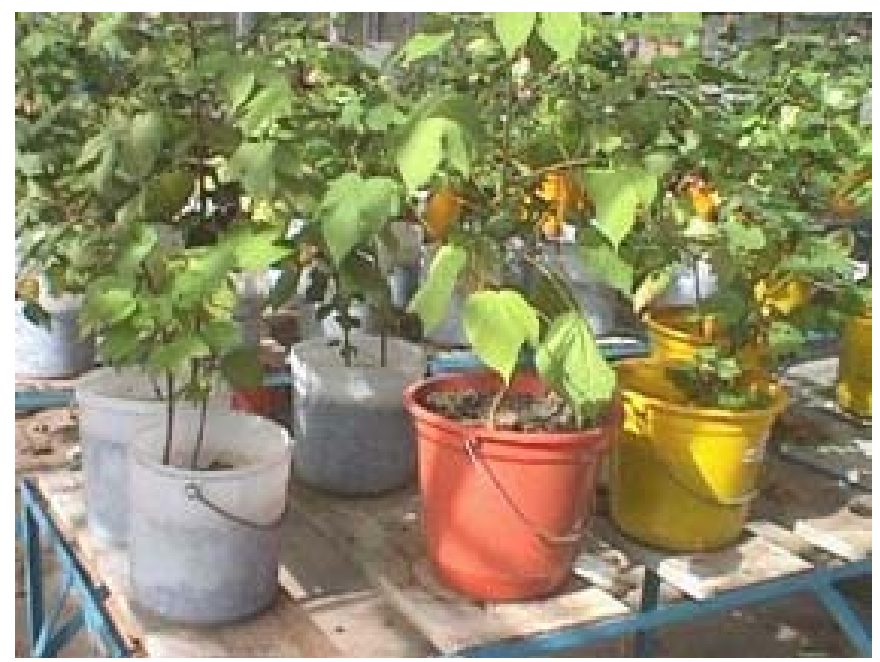

Figura 6. Detalhe de um estudo em casa de vegetação, com algodoeiro herbáceo, com vasos de cor e formas (tamanho) diferentes

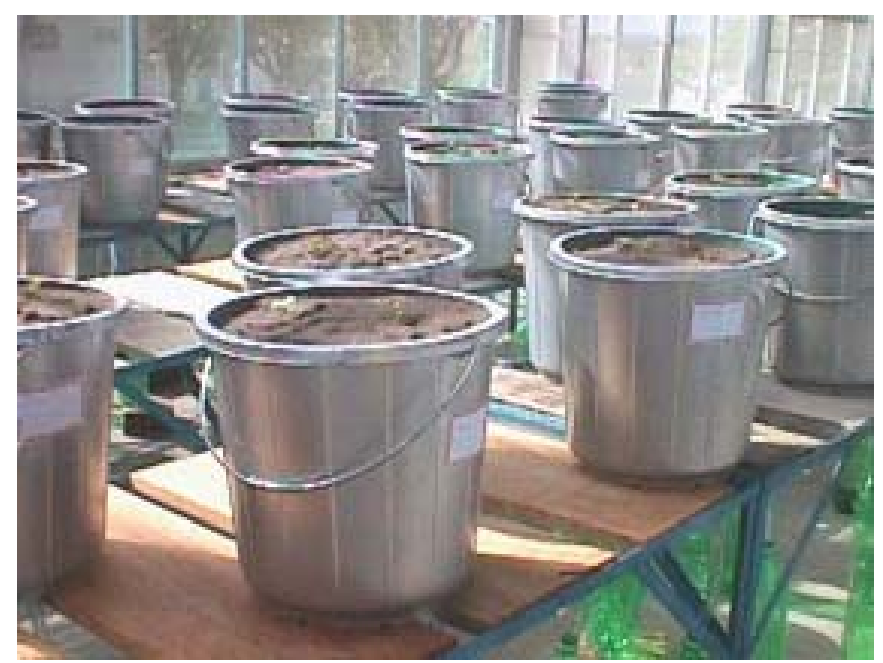

Figura 7. Vasos uniformizados no tamanho e cor

interagir com os efeitos dos tratamentos. Para uniformizar a cor dos vasos recomenda-se pintá-los com tinta prateada fosca como pode ser observado na Figura 7.

O tamanho (capacidade) dos vasos a ser escolhido depende do tipo de estudo, da espécie-teste e das variáveis que serão estudadas. Por exemplo, no caso do algodoeiro herbáceo, em estudos envolvendo água (níveis, condições de estresses, excesso e deficiência, qualidade etc) e adubação, considerando-se que serão mensuradas variáveis envolvidas na produção, tais como número de frutos por planta, peso de capulho e produção por planta, o vaso não pode ter capacidade inferior a $25 \mathrm{~L}$, sendo o ideal de 50 a $60 \mathrm{~L}$ para a planta externar todo o seu potencial. Vasos pequenos não são recomendados pois, as vezes, as plantas, dependendo do tratamento, nem chegam a produzir. Lima et al. (1987) estudando os fatores, tipos de solo, umidade (níveis) e adubação em algodoeiro herbáceo, com vasos de $4 \mathrm{~kg}$, concluíram que a quantidade de material do solo $(3,9 \mathrm{~kg})$ foi insuficiente para o crescimento das plantas em condições de baixa fertilização, o que, aliás, era esperado. Na verdade, o crescimento da maioria das espécies, é do tipo alométrico, havendo relação constante entre o crescimento da fitomassa epígea (parte aérea) com a fitomassa hipógea (raízes), sendo que no caso do algodoeiro é de $45^{\circ}$, ou seja, perfeita, como $\operatorname{tg} 45^{\circ}=1$, e assim $\operatorname{tg}^{-1} 1=45^{\circ}$. Em estudos envolvendo água, além do tamanho dos vasos, que deve ter, no mínimo, $20 \mathrm{~L}$ de capacidade para a maioria das espécies anuais, deve-se debitar a fitomassa das plantas, a medida em que as mesmas forem crescendo; para tal, deve-se ter, de cada tratamento, pelo menos duas a três repetições extras para, periodicamente, se sacrificar as plantas e se adicionar o seu peso seco, debitando do peso da água a ser reposta, pois a biomassa vem, na maior proporção, da própria água (oxigênio e hidrogênio) e do ar, o $\mathrm{CO}_{2}$ que, juntos, representam mais de $95 \%$ da fitomassa.

\section{CONCLUSÕES}

Em estudos em casas-de-vegetação e telados deve-se ter cuidado com a uniformização do ambiente, em termos do tipo de cobertura da estrutura, que deve ser de vidro ou plástico transparente, tamanho de vasos, mínimo de $20 \mathrm{~L}$ de capacidade por plantas anuais, cor de vasos (todos da mesma cor e pintados de prateado fosco), disposição dos vasos ao longo da bancada, sentido Norte-Sul verdadeiro e outros cuidados, para se reduzir o erro experimental e a variabilidade dentro dos tratamentos.

\section{LITERATURA CITADA}

Beltrão, N.E. de M. Caracterização de sistemas e tecnologias de cultivo para a cotonicultura herbácea, com ênfase para o Norte de Minas Gerais. Campina Grande: EMBRAPA-CNPA. 1997. 56p. Documentos, 55

Beltrão, N.E. de M.; Azevedo, D.M.P. de. Defasagem entre a produtividade real e potencial do algodoeiro herbáceo: limitações morfológicas, fisiológicas e ambientais. Campina Grande: EMBRAPA-CNPA, 1993. 108p. Documentos, 39

Boulard, T.; Wang, S.; Haxaire, R. Mean and turbulent air flows and microclimatic patterns an on empty greenhouse tunnel. Agricultural and Forest Meteorology; Amsterdam, v.100, p.169-181, 2000.

Kendrick, R.E.; Frankland, B. Fitocromo e crescimento vegetal. São Paulo: Editora da Universidade de São Paulo, 1981. 76p. Larcher, W. Ecofisiologia vegetal. São Carlos: RIMA. 2000. $531 \mathrm{p}$.

Levitt, J. Responses of plants to envoronmental stresses. New York: Academic Press, 1972. 697p.

Li, S.; Kurata, K.; Takakura, T. Direct solar radiation into row crop canopires in a lean-to greenhouse. Agricultural and Forest Meteorology; Amsterdam, v.100, p.243-253, 2000.

Lima, M.L. de; Bezerra, J.E.S.; Carvalho, H.O. Efeitos em vasos do tipo de solo, umidade e fertilizantes no algodoeiro herbáceo. Pesquisa Agropecuária Brasileira: Brasília, 18, n.8, p.871-877, 1987. 
Magalhães, A.C.N. Fotossíntese. In: Ferri, M.G. (ed.). Fisiologia vegetal 1. São Paulo: Editora da Universidade de São Paulo, 1979. p.117-163.

Mota, F.S. da. Meteorologia agrícola. São Paulo, SP: Nobel, 1976.376p.

Nobel, P.S. Introduction to biophysical plant physiology. San Francisco: W. H. Freeman and Company, 1974. 488p.
Oliveira, M.R.V. de. O emprego de casas-de-vegetação no Brasil: vantagens e desvantagens. Pesquisa Agropecuária Brasileira, Brasília, v.30, n.8, p.1049-1060, 1995.

Street, H.E.; Opik, H. Fisiologia dos angiospermas. Crescimento e desenvolvimento. São Paulo: Editora da Universidade de São Paulo, 1974. 332p. 